\title{
Arms control for armed uninhabited vehicles: an ethical issue
}

\author{
Jürgen Altmann
}

Published online: 21 March 2013

(C) The Author(s) 2013. This article is published with open access at Springerlink.com

\begin{abstract}
Arming uninhabited vehicles (UVs) is an increasing trend. Widespread deployment can bring dangers for arms-control agreements and international humanitarian law (IHL). Armed UVs can destabilise the situation between potential opponents. Smaller systems can be used for terrorism. Using a systematic definition existing international regulation of armed UVs in the fields of arms control, export control and transparency measures is reviewed; these partly include armed UVs, but leave large gaps. For preventive arms control a general prohibition of armed UVs would be best. If that is unattainable, several measures should be taken. An explicit prohibition of autonomous attack, that is without a human decision, should be added to IHL. Concerning armed UVs remotely controlled by a human soldier, recommendations differ according to type or mission. New kinds of uninhabited nuclear-weapon carriers should be banned. Space weapons should be prohibited in general. UVs smaller than $0.2-0.5 \mathrm{~m}$ should be banned. Bigger remotely controlled armed UVs not equipped with weapons of mass destruction should be subject to numerical limitations in various categories. For these the Treaty on Conventional Armed Forces in Europe is an important precedent.
\end{abstract}

Keywords Unmanned vehicle - Uninhabited vehicle . Military robot · Arms control · Disarmament · UAV . UGV · USV · UUV · UMS

\section{Introduction}

When thinking of ethical issues linked to armed vehicles without a human operator on board arguments about the law of armed conflict (also called international humanitarian law, or ius in bello in the traditional just-war theory, Walzer 1977) come to mind first, and the discussion in the scientific literature has mostly focused on these issues (e.g. Asaro 2008; Sparrow 2007; Lin et al. 2009; Krishnan 2009: Ch. 5). ${ }^{1}$ They are about behaviour when war takes place. However, there is an important other dimension: the prevention of war in the first place, following the prohibition of violence between states enshrined in the UN Charter ${ }^{2}$ and the prerogative of peace contained in many other international documents. ${ }^{3}$ (In the ius ad bellum part of just-war theory one can find this dimension in the strict conditions for when it can be justified to go to war.) Acknowledging that the preparations for war can make war more likely (one aspect of the so-called security dilemma), ${ }^{4}$ the international

\footnotetext{
${ }^{1}$ See also many articles in this issue and the references given there.

2 Paragraphs 3 and 4 of Art. 2 of the UN Charter read (UN Charter 1945): “3. All Members shall settle their international disputes by peaceful means in such a manner that international peace and security, and. justice, are not endangered." "4. All Members shall refrain in their international relations from the threat or use of force against the territorial integrity or political independence of any state, or in any other manner inconsistent with the Purposes of the United Nations.".

${ }^{3}$ For example in the preambles of the Nuclear Non-Proliferation Treaty (1968) and the Vienna Document 1999 of the Organization for Security and Cooperation in Europe.

${ }^{4}$ In a basically anarchic international system the states maintain armed forces for their security, thereby creating mutual threats and overall diminishing the security of all. One way out of the security dilemma is agreed limitation of forces (arms control) with adequate verification of compliance.
} 
community has long declared the goal of "general and complete disarmament under strict international control". 5 Unfortunately the mechanisms prescribed in the UN Charter for maintaining the peace and stopping aggression have mostly not yet been implemented, ${ }^{6}$ and states continue to more rely on self-defence allowed in Art. 51 "if an armed attack occurs against a Member of the United Nations, until the Security Council has taken measures necessary to maintain international peace and security".

Even though general and complete disarmament has remained on the rhetorical level, partial measures of arms limitations have been agreed upon during the Cold War as well as soon after its end. Concerning nuclear armaments arms-control treaties were concluded between the USA and the Soviet Union/Russia, ${ }^{7}$ other aspects were regulated by multilateral or global treaties. ${ }^{8}$

Different from the ethics of armed conflict, the ethics of arms control is not often discussed explicitly. ${ }^{9}$ It has been a sideline in much of the debate about the ethical dimensions of nuclear deterrence (e.g. Dean 1982; Fisher 1985: Ch. 9; Finnis et al. 1987: Chs. XII, XIII). In recent years, raising the ethical awareness of life-science researchers has become a major concern of the states parties to the Biological and Toxin Weapons Convention (e.g. Millett 2011). While there is little doubt that chemical and biological weapons of mass destruction are outlawed rightly and the conviction is rising that nuclear weapons should be prohibited too (see many statements by former and present high-level politicians and military officers), conventional weapons can increase the likelihood of war in their own right (and, as long as nuclear weapons exist, conventional war between nuclear states or their allies brings the risk of escalation to nuclear war). If new classes of conventional weapons are emerging, as is the

\footnotetext{
5 Various resolutions of the UN General Assembly (e.g. UN GA 1961); taken up in the preambles of many arms-control and disarmament treaties, e.g. the Biological and Toxin Weapons Convention (BTWC 1972).

${ }^{6}$ This holds for making available armed forces to the Security Council, holding immediately available national air-force contingents, and the establishment of the Military Staff Committee (Arts. 43-47). In recent cases when the UN Security Council was not blocked by a veto, it has entitled unspecified states to take military action, for example with the authorisation of an International Security Assistance Force for Afghanistan (UN SC 2001). UN peace-keeping operations are different since they occur with the consent of the concerned parties; they are not mentioned in the Charter.

7 Most recently in the New Strategic Arms Reduction Treaty of 2010.

${ }^{8}$ Multilateral: e.g. Treaty on Conventional Armed Forces in Europe (1990), now heavily endangered; global: e.g. Biological and Toxin Weapons Convention (1972), Chemical Weapons Convention (1993), Comprehensive Nuclear Test Ban Treaty (1996). For a systematic presentation see e.g. Goldblat (2002).

9 One can make the point that the criterion "war as the last resort" of the ius ad bellum part of just-war theory (Walzer 1977) can be linked to arms control if the security dilemma is added to the considerations.
}

case with armed uninhabited vehicles, they should be assessed with respect to questions such as: Do they make war more likely? Do they raise other dangers? Envisioned shortterm military advantages should be weighed against probable long-term consequences for national and in particular international security.

Several arms-control treaties contain preventive elements, that is they prohibit or limit potential future weapons or technologies, often by including not only deployment and use, but also development and testing. ${ }^{10}$ Such preventive arms control is advisable whenever a new military technology can endanger peace, in particular stability between potential opponents, international humanitarian law, or bring dangers to society or the environment already in peacetime (see "Reasons for armed-UV arms control"). Finding out if such criteria are fulfilled is one of the subjects of military-technology assessment.

Uninhabited vehicles (UVs) promise many military advantages. ${ }^{11}$ They are already widely used, at present mainly air vehicles (UAVs) for surveillance and reconnaissance, ${ }^{12}$ ground and water UVs are less advanced. ${ }^{13}$ The trend of arming UVs is spreading to more countries. ${ }^{14}$ For the time being, weapons release is done under remote control, with a "human in the loop". However, the US military are discussing about the option of autonomous machine attack (e.g. Canning 2006; US DoD 2007, 54; US DoD 2009, 10) and have funded research in this direction (Arkin 2009; Lin et al. 2009); recently the US Department of Defense has issued a directive on "autonomy in weapon systems" (US DoD 2012).

Thus analyses about potential dangers from armed UVs and options for preventive arms control are urgently needed. Some literature exists already, but much of it remains on a general level. In the context of military-technology

\footnotetext{
10 The most important examples: Nuclear-weapon tests are prohibited by the nuclear Test Ban Treaties (Partial 1963, Comprehensive 1996). Development is explicitly included in the list of prohibited activities in the Biological and Toxin Weapons Convention (1972) and the Chemical Weapons Convention (1993).

11 The US DoD (2009: 19-20) mentions: replacement of humans in dull, dirty or dangerous missions; for UAVs: higher survivability, increased endurance, tolerance to higher G-forces, smaller sizes and thus signatures; for maritime and ground UVs: force multiplication and risk reduction.

12 More than 75 countries operate, develop, manufacture or export uninhabited air vehicles, most of them unarmed (US GAO 2012, see also Daly 2008, 2010).

${ }^{13}$ With the exception of small uninhabited ground vehicles for bomb disposal, remotely controlled from up to a kilometre (US DoD 2009: App. B).

${ }^{14}$ Daly (2010) contains 11 countries (plus the "International" category) with UAV types that are or could be armed, including development projects. At present, the USA, UK, Israel and Iran seem to be the only countries with deployed armed UAVs; the UK flies US types (RAF 2012). A Chinese producer is keen on exporting "attack drones" (Wan and Finn 2011).
} 
assessment of microsystems technology Altmann (2001: Chs. 6-8) recommended a ban of mini-/micro-robots. Discussing military nanotechnology applications under criteria of preventive arms control, Altmann and Gubrud (2004) and Altmann (2006: Chs. 5-7) recommended a general prohibition of armed UVs; if that is not achievable, they demanded bans on autonomous attack, on small UVs, on qualitatively new types of nuclear-weapon carriers and on space weapons. Altmann $(2009,2012)$ has given a relatively detailed assessment of (armed and unarmed) UVs under preventive-armscontrol criteria together with preliminary recommendations for arms control along the lines of Altmann (2001, 2006). Citing many sources, Sparrow (2009) gave a series of arguments for arms control for "robotic weapons" and proposed to start a discussion about it. He recommended restrictions on the range and mission length, or a prohibition of peacetime deployment close to other countries; at least the destructive capacity of long-range UVs should be restricted and the drive toward autonomy should be resisted. Pointing at dangerous scenarios but sceptical of a complete ban of armed military robots, Krishnan (2009: Ch. 6) discussed various options for limitations of autonomous weapons; his arguments are considered in "Options and recommendations for armedUV arms control" below. The International Committee for Robot Arms Control, founded 2009, proposed consideration of a ban on autonomous armed UVs and of limitations on "man in the loop" systems (ICRAC 2009). The International Expert Workshop "Arms Control for Robots" demanded a prohibition of autonomous weapons (plus new kinds of nuclear-weapon carriers and robotic space weapons) and quantitative as well as qualitative restrictions of armed teleoperated UVs (Statement 2010, co-signed by A. Krishnan).

A group of US researchers has pointed to the military pressures for autonomous lethal robots and has called for a discussion of policies and possible restrictions (Marchant et al. 2011). Repeating the arguments from Arkin (2009) who is a co-author-they state: "The trend is clear: Warfare will continue and autonomous robots will ultimately be deployed in the conduct of warfare". They mention several narrow as well as broad ethical and policy aspects. The parts on governance provide a menu of restrictions found in international arms-control instruments and of soft law, such as codes of conduct, transgovernmental dialogue, information sharing. As hybrid form possibly leading from soft to formal law a Framework Convention could be agreed upon within which more substantive protocols could be developed gradually. No specific recommendation is given, but it seems that a ban of autonomous lethal robots is not among the solutions envisioned. ${ }^{15}$

\footnotetext{
15 This is not the place for a detailed critique, but three aspects should be mentioned: The text is somewhat inconsistent in that it accepts that autonomous lethal robots will be deployed but is open towards any
}

One can state that arguments for arms control for armed UVs have been laid out in quite some detail and that most of the existing literature has gravitated to a common set of demands, most of them on a general level. They provide important guidelines but a detailed treatment how existing arms control affects armed UVs and how gaps should be closed is still missing. This article aims to investigate these issues.

I take the prerogative of peace, the UN Charter, the goals of disarmament and arms control and international humanitarian law as the ethical/moral foundation. Under conditions of the security dilemma, in order to achieve adherence to moral imperatives with respect to armed forces and preparations for war, usually legally binding international treaties are required (arms control in the narrow sense), mostly with measures for verification of compliance. Sometimes only politically binding agreements are concluded (arms control in the wider sense, for export control or transparency measures).

Arms control depends on clear notions of the military systems in question. Thus, in the following "Nomenclature and definitional issues", I consider definitional issues. "Reasons for armed-UV arms control" summarises reasons for arms control of armed UVs. "Existing international regulation" explains how armed (UVs) are covered by existing arms-limitation agreements, export-control regimes and transparency/confidence-building measures. "Options and recommendations for armed-UV arms control" presents options and recommendations for preventive arms control, and "Conclusion" gives conclusions.

\section{Nomenclature and definitional issues}

For considerations about limitations and in particular for the contents of arms-control treaties the categories of military systems are important; even more important are the definitions of the categories.

In particular with uninhabited aircraft many different terms have been used, for example drone, remotely piloted vehicle, air robot, unmanned aerial vehicle. For a systematic approach one can follow the nomenclature of the US Department of Defense (DoD) which in its attempt to join the activities of the armed services speaks of "unmanned

\section{Footnote 15 continued}

solution that the international community will arrive at. The discussion of existing arms-control treaties is on a general level, in particular the CFE-Treaty inclusion of armed UVs is not mentioned (see "Existing arms-control treaties" of the present article). The comparison with many international technology-governance mechanisms neglects the special conditions that hold for limitation of military uses of technologies (mainly friction with the goal of victory should war occur and the need for verification while protecting military secrets, see Altmann (2006): Sect. 5.1). 
vehicles", with sub-categories according to the medium: "unmanned air/ground/maritime (/surface/undersea) vehicles" with the acronyms UAV/UGV/UMV(/USV/UUV). The notion "unmanned systems" (UMS) with "unmanned air systems" (UAS) etc. is used to include other components, such as a ground control station, a data link, a maintenance set and, for some, launch equipment. I follow this usage here, but for gender neutrality will rather speak of "uninhabited vehicles". For completeness outer-space vehicles have to be added, and one has to keep in mind that there can be vehicles capable of moving in more than one medium, for example transatmospheric ones as envisioned by the USA for the so-called "Prompt Global Strike" (e.g. Sanger and Shanker 2010). The "robot" notion is avoided, because it is too unspecific-on the one hand it has connotations to humanoid forms and autonomy, on the other it is also used for fixed industrial robots.

The definitions used here follow a systematic and generic approach:

An uninhabited vehicle (UV) is a vehicle which does not carry a human operator. Usually its motion can be controlled and in most cases it is powered.

A vehicle is an (at least partly) artificial object which can move — on land, at sea, in air or outer space—and can carry something.

An uninhabited vehicle is denoted as armed if it carries a weapon or acts as a weapon, weapon meaning a device for physical damage or bodily harm.

An autonomous armed UV is one that can select targets and attack them without human decision or participation (except for a general authorisation).

(The UV definition of the US DoD is narrower and arbitrarily excludes certain categories that are clearly uninhabited/unmanned and are vehicles, such as ballistic and cruise missiles, torpedoes and satellites. ${ }^{16}$ The DoD

\footnotetext{
16 The definition reads (US DoD 2007: 1, emphasis original):

"Unmanned Vehicle. A powered vehicle that does not carry a human operator, can be operated autonomously or remotely, can be expendable or recoverable, and can carry a lethal or nonlethal payload. Ballistic or semi-ballistic vehicles, cruise missiles, artillery projectiles, torpedoes, mines, satellites, and unattended sensors (with no form of propulsion) are not considered unmanned vehicles. Unmanned vehicles are the primary component of unmanned systems."

The US DoD is not fully consistent in listing (unpowered) tethered aerostats and mentioning manipulation arms for outer space (US DoD 2007: 97-102, 43). The exclusion of artillery projectiles (without capability to change the trajectory), mines and unattended sensors (both immobile) makes sense technically. But ballistic missiles carry a payload (as do space-launch "vehicles"), there are clear similarities between cruise missiles (in the future with in-flight re-targeting) and some new types of UAV (using a launch rail, expendable) as well as between torpedoes and new UUVs. Functional satellites do need to control their orbit actively.
}

definition of an autonomous weapon system is similar to the one given here for an autonomous armed UV. ${ }^{17}$ ) The definition chosen excludes immobile armed robots as already deployed at the demilitarised zone between South and North Korea and which may find future use at perimeters of sites. ${ }^{18}$

Despite the effort to be systematic, some grey areas are unavoidable ${ }^{19}$ and additional clarification will be needed now and then. Since the trend towards armed UVs is mostly about new types, it is sensible to focus considerations and limitation mostly on these, keeping in mind that the other, established classes need to be included in the regulation to avoid loopholes.

\section{Reasons for armed-UV arms control}

Armed UVs can bring dangers in many respects; mention has been made, among others, of a play-station mentality among the operators, an increased propensity in particular of democracies to war, an increased likelihood of accidental war, violations of IHL or international human-rights law (e.g. Asaro 2008; Sparrow 2009; Singer 2009; Krishnan 2009; Sharkey 2010; Sauer and Schörnig 2012; Sharkey in press). The dangers are summarised here in short, following the systematic assessment under the criteria of preventive arms control by Altmann $(2009,2012)$. These criteria can be used to find out whether preventive limitation of a new technology, system or material with potential military relevance should be considered. The criteria have been categorised in three groups: 1. Adherence to and further development of effective arms control, disarmament and international law; 2. Maintain and improve stability, 3. Protect humans, environment and society (Altmann 2006: Ch. 5 and references).

In the area of arms control and disarmament, new nuclear-armed UAVs could undermine the rules on cruise missiles and bombers of the New Strategic Arms Reduction Treaty between the USA and Russia (New START 2010). Nuclear hypervelocity missiles and transatmospheric vehicles_-which would fly aerodynamically over a significant portion of their trajectories-could do the same with

\footnotetext{
17 "[A]utonomous weapon system. A weapon system that, once activated, can select and engage targets without further intervention by a human operator. This includes human-supervised autonomous weapon systems that are designed to allow human operators to override operation of the weapon system, but can select and engage targets without further human input after activation." (US DoD 2012).

18 Problems from immobile armed robots are much smaller than from mobile ones (that is, armed UVs). Specific regulation for the former could be attached to armed-UV regulation.

${ }^{19}$ For example: Where is the transition from a ballistic projectile to a (guided) vehicle? What is the minimum amount of implanted artifact that would make a (natural) animal a vehicle in the present sense?
} 
respect to the ballistic missiles. Nuclear UAVs with ranges between 500 and $5,500 \mathrm{~km}$ would endanger the Intermediate Range Nuclear Forces Treaty (INF Treaty 1987, between USA and Soviet Union/Russia) that prohibits nuclear ground-launched ballistic and cruise missiles in this range interval (INF Treaty 1987) - the introducing country would probably argue that such UAVs are no cruise missiles. Introduction of nuclear intermediate-range UAVs by other countries-that are not bound by the INF Treaty-would raise the question how long USA and Russia would keep the Treaty alive. Conventionally armed UVs in Europe fall under the Treaty on Conventional Armed Forces in Europe (CFE Treaty 1990) as discussed in "Existing international regulation" below, but if some of them get smaller than traditional systems arguments will probably be made that they should count differently, leading to grey areas and complicated discussions. Also here developments outside of Europe can contribute to undermining.

Concerning arms control in outer space, uninhabited satellites for docking, servicing and manipulation provide possibilities for anti-satellite attack, endangering the general ban on space weapons that the international community is requesting since decades.

With respect to international humanitarian law (IHL), malfunctioning UVs must not produce (civilian) damage. A positive factor of armed U(A)Vs in respect of discrimination is that their attacks can be better directed than artillery and aerial bombs and that they allow real-time assessment of a scene with immediate reaction to changes; both can reduce collateral damage. On the other hand, experiences with US attacks in Afghanistan, Iraq and Pakistan show that often civilians are attacked and killed; obviously the video image from a considerable distance does not allow to identify a person or to reliably recognise a weapon. The distance from the scene and the computergame-like interface-being in an office environment in the home country - can make shooting easier. But a pilot of a combat aircraft is also removed from his/her target, and different from the former the UAV operator can look at the results of the attack for much longer (at least in very asymmetric settings where the opponent has no means of threatening the UAV). Obviously soldiers on the ground could act much more discriminately — checking the identity of persons, searching for weapons, arresting someonewhereas aircraft-with or without crew on board-have attack as their only action possibility.

Autonomous machine decision when and whom to attack (Arkin 2009) will for a long time not be possible at the intelligence level of a human commander (Sharkey 2010, in press, see also "Limitation or ban of autonomous armed UVs")—and this is what IHL requires. Earlier introduction of autonomous attack-a possible consequence of various military pressures-would thus endanger IHL.

That UVs can be used to carry weapons of mass destruction, with UAVs the main option, provides another argument to consider preventive arms control.

Armed UVs can destabilise the military situation between potential opponents-that is, increase pressures to attack or react fast-in several respects. Some UAVs can penetrate deeply with little chance of being detected or defended against, for carrying out precision surprise attacks. Without humans on board they could be sent more easily and for more dangerous missions. Destabilisation would be higher if the payload might consist of weapons of mass destruction.

In a crisis, in a situation when both opponents command armed UVs and when both fleets meet at short distance, they would observe each other on high alert. Because a co-ordinated first attack could destroy many opponent UVs, shooting could start on any indication of attack, including erroneous signals. Thus war could start by uncontrolled feedback cycles between the two systems of warning and attack, in particular if they would work in autonomous mode.

Instability at the highest levels would follow if swarms of highly precise conventionally armed small UAVs could threaten nuclear-strategic targets, if small satellites could take out satellites for strategic warning, surveillance and communication, or if-in the later future-microrobots could enter military systems of an opponent covertly, to disrupt the electronics at any time.

A technological arms race in qualitative and quantitative terms has already started with armed UAVs and will soon include more countries. Armed UVs for land and sea will follow. As more countries will deploy armed UVs, this will drive efforts for defence against them and vice versa.

Horizontal and vertical proliferation of armed UAVs has started, too, and-absent international limitations-will accelerate likewise. At present there is international concern about proliferation to non-state actors, but due to their resources and (internal) power states will probably create bigger proliferation problems. In turn, non-state actors may receive armed UVs from states, in particular more advanced ones than they could fabricate by themselves. Thus, even though non-state actors will not become parties to international agreements, limitation among states would go a long way in preventing access by non-state actors.

Already in peacetime dangers to humans and dangers to society could ensue if armed UVs would fall into the hands of criminals. In particular small UAVs could make ideal terrorist tools, either for selectively attacking important persons or for mass destruction by distributing biological agents. If military systems will have been designed for such purposes the dangers would be higher. 
In sum there are strong concerns about armed UVs. Seen from a viewpoint of peace and international security plus security within societies, most of the concerns seem more important than the military advantages they can bring for the combat effectiveness of individual armed forces. Thus, there are strong arguments for including armed UVs into (preventive) arms control.

\section{Existing international regulation}

Armed uninhabited vehicles for land, water, air or outer space do not exist in a complete legal vacuum; on the contrary, beside IHL, ${ }^{20}$ they are already subject to some arms-control treaties, to export control regimes and to transparency measures. But the existing regulation leaves important gaps that should be closed.

\section{Existing arms-control treaties}

Arms-control treaties usually are concluded as legally binding agreements compliance with which is verified by the treaty parties or an international organisation. From the existing treaties at first the Biological and Toxin Weapons Convention (BTWC 1972) and the Chemical Weapons Convention (CWC 1993) — of which nearly all states are members-have to be mentioned (BTWC 1972; CWC 1993). These Conventions probibit all such weapons including carrier and dispensing systems, thus UVs must not be equipped with them.

The Intermediate Range Nuclear Forces (INF) Treaty (1987) is bilateral, between the USA and the Soviet Union/ Russia (INF Treaty 1987). For these two countries it prohibits land-based nuclear long-range cruise missiles as well as land-based nuclear ballistic missiles between 500 and $5,500 \mathrm{~km}$ range. Its effects on armed UVs are thus limited (all the more because the US Department of Defense does not count cruise and ballistic missiles as UVs).

The New Strategic Arms Reduction Treaty (New START 2010) between Russia and USA allows new types of strategic nuclear-weapons carriers, the only obligation is to notify and exhibit them to the other party (New START 2010). In the USA there is a discussion if the next generation of nuclear bombers should be uninhabited (Lowther 2009). This would not be constrained by the Treaty.

On the other hand, the Treaty on Conventional Armed Forces in Europe (CFE Treaty 1990, adapted 1999) contains relevant restrictions (CFE 1990, 1999). The Treaty was concluded between the member states of the North Atlantic Treaty Organisation (NATO) and the former

\footnotetext{
${ }^{20}$ For a discussion of armed UAVs under IHL see e.g. Boothby (2011).
}

Warsaw Treaty Organisation (WTO, dissolved in 1991) and holds for their European territories from the Atlantic to the Urals. ${ }^{21}$ The CFE Treaty limits five major categories of conventional armament: battle tanks, armoured combat vehicles, artillery, combat aircraft and attack helicopters. For each category there are limits for the holdings in the member states. ${ }^{22}$ When the Treaty text was elaborated, the negotiators took possible future development of uninhabited combat vehicles into account. Consciously they designed the definitions of the categories in such a way that they are independent of whether there is a crew on board or not. According to Article II par. 1 of the Treaty,

"Battle tanks are tracked armoured fighting vehicles which weigh at least 16.5 metric tonnes unladen weight and which are armed with a 360-degree traverse gun of at least $75 \mathrm{~mm}$ calibre." (Section (C) $)^{23}$ "The term 'combat aircraft' means a fixed-wing or variable-geometry wing aircraft armed and equipped to engage targets by employing guided missiles, unguided rockets, bombs, guns, cannons, or other weapons of destruction, as well as any model or version of such an aircraft which performs other military functions such as reconnaissance or electronic warfare." (Section $(\mathrm{K}))^{24}$

Similarly, the definitions of a "heavy armament combat vehicle" (Section (D)) and of combat/attack helicopters (Sections $(\mathrm{L})-(\mathrm{O})$ ) do not mention persons on board. In addition to the definitions there is a Protocol on Existing Types of Conventional Armaments and Equipment where the states list their types of Treaty-limited weapons and carriers. This Protocol is to be updated periodically.

The definitions of the land vehicles contain minimum masses and gun calibres so that new uninhabited types below these thresholds are not constrained by the Treaty and could be deployed in unlimited numbers. The definitions of combat aircraft and combat/attack helicopters, on the other hand, are independent of mass or size. Taken verbatim they hold also for small and very small armed uninhabited aircraft. Thus, all such mini-/micro aircraft would count, and the states would have to remove one

\footnotetext{
21 Today the Eastern side has been reduced to Armenia, Azerbaijan, Belarus, Georgia, Kazakhstan, Moldova, Russia and Ukraine while several former WTO states have joined NATO.

${ }^{22}$ In addition to the limitations in the five categories, the Treaty stipulates information exchanges on other systems such as armoured personnel carrier look-alikes, armoured vehicle-launched bridges, trainer aircraft, transport helicopters. These are subject to inspections as well.

${ }^{23}$ Strictly speaking the kilogram and the ton are units of mass, not weight which is a force for which the unit is Newton. Thus I use "mass" except in verbatim quotes.

${ }^{24}$ The definitions contain some additional explanations.
} 
large armed air vehicle for each newly introduced small one.

Unfortunately the CFE Treaty-that was adapted in 1999 to the situation after the Cold War-is suspended since 2007 (Schmidt 2008); its Protocol on Existing Types of Conventional Armaments and Equipment (POET) was not updated since $1997 .^{25}$ The Treaty should be re-activated or modernised urgently (Schmidt and Hartmann 2011). In particular the POET should be updated regularly. However, uninhabited combat vehicles introduced in Europe in the future can be notified and subjected to on-site inspections independently. ${ }^{26}$

But even if this were done, the regulation would remain limited to Europe. No comparable treaties exist in other regions of the world so that armed UVs can be introduced there in unlimited numbers.

The Outer Space Treaty (1967) prohibits weapons of mass destruction on space objects, independent of whether there is a crew on board or not (OST 1967). Other space weapons are not yet prohibited, unfortunately, and the moratorium on anti-satellite (ASAT) weapons that the USA and Russia have kept in the 1980s and early 1990s is no longer valid, with ASAT capabilities provided by ballisticmissile defence systems and a first ASAT test by China (Grego 2012).

\section{Export control}

Contrary to arms-control treaties export-control agreements are not legally, but only politically binding. They rather establish guidelines. The individual decision about approval or denial of an export licence is made by the respective state, potentially after consultation with others.

In the Missile Technology Control Regime (MTCR) 34 countries have agreed to restrict exports of potential carrier systems for mass destruction weapons. The members are mainly Western countries plus Russia and Ukraine; other missile exporters such as China, Israel, India, Iran, North Korea or Pakistan are no members (China and Israel have stated that they will adhere to the regime). Category I of the MTCR contains items that should not be exported except in rare cases; it contains, among others: "Complete unmanned aerial vehicles systems (including cruise missiles, target drones and reconnaissance drones) capable of delivering at least a $500 \mathrm{~kg}$ 'payload' to a 'range' of at least $300 \mathrm{~km}$ " (MTCR 2011: 1.A.2). Category II lists items that can be exported after consideration of six criteria to do with the

\footnotetext{
$\overline{25}$ Telephone communication with Zentrum für Verifikationsaufgaben der Bundeswehr, Geilenkirchen, Germany.

26 That the Predator and Reaper armed UAVs have not been notified by the USA and UK up to now is due to the fact that they are deployed in the Middle East, not in Europe from the Atlantic to the Urals.
}

risk of misuse. Here UAV systems with at least $300 \mathrm{~km}$ range are included, independent of payload (MTCR 2011: 19.A.2). If there is autonomous flight control or remote control beyond visual range and the UAV "incorporates an aerosol dispensing system/mechanism with a capacity greater than 201 " it falls under Category II likewise, independent of its payload and range. In addition, the list contains production facilities and many technologies relevant for UVs, for example engines, autopilots, launch systems, wind tunnels and test stands. ${ }^{27}$

Many more countries take part in the Hague Code of Conduct against Ballistic Missile Proliferation (HCOC). The 130 member states commit to export control and to transparency measures, but only for ballistic missiles (HCOC 2011). Cruise missiles and other armed UAVs are not covered.

In the Wassenaar Arrangement 40 members have agreed to control exports of conventional weapons and sensitive dual-use goods and technologies "to regions and states with situation/behavior representing serious concerns to the members", to prevent "potentially destabilising accumulations of conventional weapons". Its lists mention certain robots, $^{28}$ military UAVs (Wassenaar 2011: ML10), unmanned submersible vehicles for depths below 1,000 $\mathrm{m},{ }^{29}$ underwater robots, ${ }^{30}$ UAVs with autonomous flight control and navigation capability or remotely controlled beyond visual range (Wassenaar 2011: 9.A.12) as well as equipment and various technologies for these UVs. Also here several important producing and exporting countries do not participate.

Whereas the three regimes mentioned thus far are asymmetric - the member countries use the respective military systems and technologies themselves while trying to block access by (some) others - there are also export controls that are linked to near-universal treaties. ${ }^{31}$

To minimise the risk of chemical and biological weapons proliferation while not impeding the "normal trade of materials and equipment used for legitimate purposes", the Australia Group (with 41 mostly Western members, all

\footnotetext{
$\overline{27}$ The UAV category 19.A.2. is mentioned at 30 different places (MTCR 2011).

${ }^{28}$ Robots for military use, robots protected against ballistic fragments, or robots for work in an electromagnetic-pulse environment (Wassenaar 2011: ML17.e).

29 Tethered: self-propelled or with fibre-optic data link; untethered: autonomous course or acoustic or optic data link (Wassenaar 2011: 8.A.1).

${ }^{30}$ With dedicated computer, controlled by force, torque or distance sensors, or able to apply force $\geq 250 \mathrm{~N}$ or torque $\geq 250 \mathrm{NM}$ using titanium alloys or composite materials (Wassenaar 2011: 8.A.2.h).

31 The two export-control regimes connected to the Nuclear NonProliferation Treaty (NPT, of 1968), the Nuclear Suppliers Group (NSG 2011) and the Zangger Committee (Zangger 2011), concern nuclear materials and equipment and are not directly relevant to UVs.
} 
parties to the CWC and the BTWC) has set up guidelines and control lists. The "Control List of Dual-use Biological Equipment and Related Technology and Software" mentions "spraying or fogging systems, specially designed or modified for fitting to aircraft, lighter than air vehicles or UAVs" as well as "aerosol generating units" for the same if they are "capable of delivering, from a liquid suspension, an initial droplet 'VMD' of less than 50 microns at a flow rate of greater than two litres per minute" (VMD: volume mean diameter), and related technology (Australia Group 2011a, b: I.8., II). ${ }^{32}$

While export controls can delay the proliferation of armed UVs, they do not offer a sustainable solution, because the producing states are not constrained in their own armament and in exports to their allies and friends.

Transparency measures/confidence and security building measures

Peace and security between potential opponents can be supported by creating transparency. Confidence and security building measures mostly do not contain limitations, but can counteract exaggerated threat perceptions and ensuing armament cycles and instability, and may lead to more restraint.

Most notable is the Vienna Document 1999 (reissued slightly updated 2011) (VD 2011) concluded in the framework of the Organization for Security and Cooperation in Europe (OSCE). The document is politically, not legally binding; it includes limits on manoeuvre sizes and verification by inspections. Among its many rules is annual exchange of data relating to major weapon and equipment systems, including new types, as well as of information on plans for the deployment of such (VD 2011: Pars. 11-13). This obviously applies to future armed UVs that would be deployed in Europe. ${ }^{33}$

Another transparency measure is the United Nations Register of Conventional Arms (UN Register 2007). Here data on international transfers (and national holdings) of arms are to be provided by the exporting as well as the importing states. Not all countries report, and not all reports are complete. The definitions of the weapons categories, transfers and holdings of which are to be reported, are similar to the ones of the CFE Treaty, ${ }^{34}$ that is they

\footnotetext{
32 The "Control List of Dual-Use Chemical Manufacturing Facilities and Equipment and Related Technology and Software" (Australia Group 2011a) is more specific and does not mention UVs.

33 Also here the USA and the United Kingdom have not provided data on their armed Predator and Reaper UAVs because they are deployed outside of Europe.

${ }^{34}$ E.g. "Battle tanks: Tracked or wheeled self-propelled armoured fighting vehicles with high cross-country mobility and a high-level of self-protection, weighing at least 16.5 metric tons unladen weight,
}

apply independently of whether there are persons on board or not. In addition there are two categories "Warships" and "Missiles and missile launchers". The latter explicitly contains "remotely piloted vehicles" with characteristics of rockets, ballistic or cruise missiles "capable of delivering a warhead or weapon of destruction to a range of at least $25 \mathrm{~km} "{ }^{35,36}$

Gaps in international regulation

Even though armed UVs are included in existing armscontrol treaties, export-control regimes or transparency measures, the regulation is far from satisfactory. There are important deficiencies in all three areas, some apply more generally than to UVs. Limits on nuclear-armed ballistic and cruise missiles apply only to the USA and Russia, other ballistic and cruise missiles are not covered at all. The CFE Treaty does not hold outside of Europe. Maritime systems are not covered at all. Export controls are asymmetric and non-comprehensive. Transparency measures are not legally binding and do not include limitation of arms.

Thus, in order to prevent or at least contain the dangers mentioned in "Reasons for armed-UV arms control", international treaties systematically limiting armed UVs are needed on the global scale.

\section{Options and recommendations for armed-UV arms control}

Complete ban on armed UVs

Considering that armed UVs bring the next arms-race wave, can increase the probability of war, endanger IHL and provide new possibilities for terrorist attacks, one is led to the conclusion that it would be best to prohibit at least the new ones outright from the beginning. To allow fast agreement on the urgent issue states should not be required to withdraw widely deployed, traditional systems. If the general, systematic definition of UV from "Nomenclature and definitional issues" is used, special exceptions would

Footnote 34 continued

with a high muzzle velocity direct fire main gun of at least $75 \mathrm{~mm}$ calibre." The other CFE-like categories are: Armoured combat vehicles, Large-calibre artillery systems, Combat aircraft and Attack helicopters.

35 Thus some armed UAVs may be covered doubly.

36 The UK has reported its holdings of Reaper UAVs since 2007 under Category "IV. Combat/Military Aircraft". For 2007 it reported the import of two Reapers from the USA (which was not reported as export by the USA) (UN SG 2008-2012). 
thus be needed for cruise missiles and ballistic missiles with pre-programmed targets that exist already. ${ }^{37}$ Exceptions should also be allowed for guided weapons with an automatic shooting or launching mode or that search for a target, if these weapons existed already in 2000, if target recognition is simple and if human reaction is technically excluded or would take too long; these weapons are mainly torpedoes, systems for close-range ship defence and for air defence. Unarmed UVs for reconnaissance, communication etc. would not be limited. Verification could rely on on-site inspections of sites with holdings of UVs and of testing and training sites with close access to and demonstrations of the vehicles so that inspectors can confirm that there are no bomb bays and no hard points under the fuselage or the wings of UAVs, no machine guns or the like on UGVs and USVs, and that weapons release is neither tested nor trained.

For most countries this approach would be fully preventive- the USA, Israel, UK and Iran would have to abolish some armed-UAV types introduced recently (only very few land and sea systems have been deployed already). However, given the big and increasing importance that the USA and UK, plus Israel, assign to attacks by armed UVs in the Middle East it is improbable that they will agree to such a comprehensive prohibition any time soon. Then second-tier countries such as Russia and China, but also other European NATO countries, would also not want to preclude the armed-UV option. The unwillingness of the USA is the main reason why Krishnan (2009: 157) rejected a ban of armed robots. ${ }^{38}$ Pragmatically accepting the difficulties of achieving a total ban on armed UVs the 2010 Berlin expert workshop restricted its demands to a ban on autonomous attack and various limitations on teleoperated armed UVs (Statement 2010). ${ }^{39}$ On the other hand, foreign-troop withdrawal from Afghanistan has been announced for 2014, so that urgent motives for military UAV attacks to protect the US and UK troops will vanish. ${ }^{40}$ Principally it is conceivable that if the USA and UK think long and hard about their own security, these countries could arrive at the conclusion that a ban is in their long-term interest, but such a turn would occur only after a long time (and maybe only after a catastrophic attack).

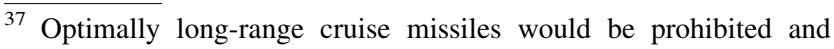
reduced to zero globally together with ballistic missiles which would also supersede arguments for ballistic-missile defence. But this is for the longer term-preventing new armed UVs (including new cruise missiles) should have priority.

${ }^{38}$ Further he argued against Western restraint because not all countries would follow suit, creating pressures to counter robotic/ autonomous weapons, so that the West should better be in the lead.

39 The present author, while favouring a total ban, is a co-drafter and co-signer of the Berlin Statement.

40 Targeted killings in Pakistan and elsewhere should not be seen as an acceptable justification for keeping armed UAVs (Heyns 2012: Sections IV D, V and refs).
}

If a comprehensive ban cannot be attained, then quantitative limits are needed, for different categories. The major categories are UVs for autonomous attack and those that are remotely controlled.

\section{Limitation or ban of autonomous armed UVs}

Krishnan (2009: 162) argued that a ban on autonomous weapons, demanding human control of weapon launch, is not an effective strategy for arms control because states are unlikely to agree on that and because verification, requiring access to the robot control software and robot memory, would be too intrusive. Nevertheless, to avoid some of the dangers from autonomous weapons, the latter should be restricted in some ways (Krishnan 2009: 161-165) ${ }^{41}$ :

- A kill-box could be defined by co-ordinates after reconnaissance would have confirmed that the box contains only military targets. The weapon could only attack within the box.

- Autonomous armed UVs should not be used among civilians.

- The firepower and range should be limited.

- A safety switch should disable the weapon after some time or if communication is lost permanently.

- A robot-anti-robot arms race leading to ever more autonomy with decreasing predictability and human control should be prevented by a prohibition of evolving or self-learning software.

Assuming that autonomous armed UVs cannot be prevented, it would be better to have such restrictions in place. However, the first two ideas would remove much of the military advantage that autonomous UVs promise by requiring that first a force should make sure that a certain area/volume box is free from civilians-maybe even by a human looking at video from a reconnaissance UV in real time, because the situation in the defined kill box may change, for example a military target may change from legitimate to illegitimate if a group of refugees approaches it. The last proposal would be difficult to define in detail (and to some extent runs counter to the explicit requirement of learning from mistakes that has been proposed for lethal autonomous robots). ${ }^{42}$ In addition verification that the control software cannot evolve would be very difficult and access to the software inside a given UV would need a degree of intrusiveness that seems unrealistic, an argument that is more applicable here than with autonomous attack in

\footnotetext{
$\overline{41}$ His other recommendations (concerning police, private companies, defensive postures, demilitarizing of artificial-intelligence research, doomsday machines) are not discussed here mainly for space reasons. 42 Arkin (2009: Sect. 10.3) foresees an "ethical adaptor" that alters its ethical base by after-action reflection, however only in an ever more restrictive way.
} 
general where Krishnan used it to dismiss a ban. If autonomous armed UVs will be introduced at all, a "robotanti-robot" arms race is bound to occur, with a slippery slope where the trend toward increasing autonomy including adaptive software would be difficult to stop.

Arkin (2009) has done research on autonomous lethal robots with the goal of their conforming to IHL and ethically outperforming human soldiers. He states that "[i]t is too early to tell whether this venture will be successful" and lists several "daunting problems remaining" (p. 211). Referring to the basic requirements of IHL, Sharkey (2010) writes that "[c]urrently and for the foreseeable future no autonomous robots or artificial intelligence systems have the necessary properties to enable discrimination between combatants and civilians or to make proportionality decisions." Given that military motives with international interactions could lead down the slippery slope towards autonomous attack before the "daunting problems" would have been solved, an explicit prohibition seems required, at least for the next decades. But there is also the fundamental question of giving a machine authority to decide on taking of a human life. ${ }^{43}$

For both reasons a simple, basic rule should be introduced into IHL: autonomous machine decisions on whom or what to attack should be prohibited at all, absolutely demanding a human in the decision chain for each single weapon release. This has been the approach of the Berlin Statement (2010) ${ }^{44}$ and can also be seen as one measure of upholding the fundamental ethical demand of making sure that humans remain in control over robots. Exceptions could hold for automatic weapons that exist already as discussed in "Complete ban on armed UVs". This general rule would exclude the military personnel-saving advantages of controlling many armed UVs by one human soldier, and it would have to be upheld against military pressures for faster reaction, but it seems justified by important higher-priority arguments. The general principle would hold for all media, including outer space, and would obviously include nuclear weapons.

Since remotely controlled UVs could be changed to autonomous mode by a simple software switch, verifying the non-existence of an autonomous attack mode in advance is hard. Hints could be gained from systematic observation of UV testing and training operations. But even if this were impossible: there is much IHL regulation that is rather about behaviour in battle than about technical properties of weapons-such as the general principle of

\footnotetext{
43 This can be seen as an important part of making sure that humans retain control over robots. On another level one can mention the requirement of an interpersonal relation between the attacking human and the victim (Sparrow 2011 and ref).

${ }^{44}$ Which has been signed by A. Krishnan, too.
}

discrimination or the prohibition to use incendiary weapons against civilians - and that can only be checked after the fact, for example by forensic analysis. Forensic analysis in the case of (new) armed UVs is strongly helped by the big amount of sensor and communication data that flow between the UV and the control station. As a corollary to the prohibition of autonomous attack there should be an obligation to record all sensor, communication and control data around every attack by an armed UV and to make it available shortly afterwards to the organisation responsible for IHL, namely the International Committee of the Red Cross (ICRC), for checking compliance with the obligation of human remote control. ${ }^{45}$ The ICRC is a strictly neutral body and states are used to its visits to prisoner-of-war camps and other, normally confidential, activities. Thus acceptance of such investigations - that would not require access to the UV control software-is conceivable. ${ }^{46}$

\section{Limitations of remotely controlled armed UVs}

\section{Special categories}

Some sub-categories of remotely controlled armed UVs should be covered by special regulation:

Armed UVs for outer space need not be limited just quantitatively - given the special difficulties in space and the earlier moratorium on anti-satellite weapons a complete prohibition is a realistic goal. Since most weapons in outer space or for outer space would be uninhabited in the first place, armed UVs for outer space are best covered by a general ban of space weapons as proposed since decades (e.g. Altmann and Scheffran 2003). ${ }^{47}$ Mistrust concerning docking satellites should be prevented by rules of the road and increased transparency.

Concerning UVs armed with nuclear weapons, the existing ones with pre-programmed targets - that is, (landand sea-based) ballistic missiles and (air- and sea-based) cruise missiles-should be reduced in the process of nuclear disarmament, and no new kinds of nuclear-armed UVs should be introduced. The third category of nuclearweapon carrier, armed bombers, should not be replaced by uninhabited aircraft. Such rules can be incorporated into the START follow-on treaty between the USA and Russia. The other nuclear-weapon states should take on the same obligations by their inclusion in nuclear-disarmament treaties at an early stage.

\footnotetext{
$\overline{45}$ This concept was presented at the Berlin Workshop 2010 by P. Asaro.

46 Many details would have to be defined and intense discussions can be foreseen to make this concept workable and acceptable.

${ }^{47}$ Note the recurring resolutions of the UN General Assembly against an arms race in outer space (most recently UN GA 2012).
} 
Armed uninhabited transatmospheric vehicles would introduce instability because of short flight times for very long ranges and because they could carry a nuclear weapon. Conventionally armed they would have very limited effect at relatively high cost. Thus a complete prohibition seems feasible and should be sought, either by a global treaty or by one among the space-faring states.

Very small armed UVs-of centimetre, millimetre or even smaller sizes-would bring particular dangers of terrorist uses and would pose very difficult verification problems. Unarmed types could be converted to armed ones without easy recognisability. Thus a general prohibition on UVs for all media that are smaller than $0.2-0.5 \mathrm{~m}$, armed or not, military or not, is recommended. ${ }^{48,49}$ Strictly limited exceptions should hold for civilian purposes such as exploration of shattered buildings.

For the other armed-UV categories (bigger than 0.2-0.5 m, non-nuclear, moving in/on land, sea or air, or hybrid forms) quantitative limitations should be introduced, optimally globally, potentially with some differentiation by region, as discussed in the following subsections.

\section{Refining the CFE Treaty}

In Europe the minimum requirement is to uphold (and revive) the CFE Treaty, counting armed land and air UVs in the respective categories. In particular the Protocol on Existing Types of Conventional Armaments and Equipment should be updated regularly, reflecting the process of introduction of armed UVs as it may unfold.

A few loopholes need to be closed and grey areas minimised: The land-vehicle definitions contain minimum criteria for unladen weight and calibre (16.5 metric tons for battle tanks, 6.0 metric tons for heavy armoured combat vehicles, $75 \mathrm{~mm}$ calibre for both). Armed land UVs below these thresholds are not limited by the Treaty. Here new categories should be introduced with maximum holdings at least for UVs of lower weights that carry a cannon, maybe even a heavy machine gun. ${ }^{50}$

The definitions of combat aircraft and combat/attack helicopters, on the other hand, are independent of weight or size. Taken verbatim any small and very small armed UAV would count, and the states would have to ponder which large aircraft they would like to forego for newly introduced small ones. This is somewhat improbable, however.

\footnotetext{
48 This prohibition should hold in general, also in case autonomous armed UVs will not be banned.

49 Krishnan (2009: 165) has taken up this demand.

50 Small arms and light weapons are not limited by the CFE Treaty, but if used in great numbers on UVs they could become a source of threat and instability.
}

When smaller armed uninhabited aircraft are to be introduced, states will likely argue that these constitute new categories for which additional numerical limits ought to be negotiated; these could be much higher (thousands, maybe tens of thousands) than those for traditional large combat aircraft (hundreds to few thousand) and attack helicopters (dozens to several hundred) (see Table 1). ${ }^{51}$ The numerical limits should be relatively stringent, reflecting the objectives enshrined in the CFE-Treaty preamble:

Establishing a secure and stable balance of conventional armed forces in Europe at lower levels than heretofore, of eliminating disparities prejudicial to stability and security and of eliminating, as a matter of high priority, the capability for launching surprise attack and for initiating large-scale offensive action in Europe.

\section{New limits outside of Europe}

The objectives of the CFE Treaty are useful for other regions as well. In principle CFE-Treaty-like limitations of conventional armament should be introduced outside of Europe, in particular in potential crisis regions such as the Near/Middle East and South Asia, including armed land and air UVs along the lines proposed for Europe. However, this would require solving very complicated political/military problems, and maritime issues would probably have to be addressed in parallel. Armed-UV developments are proceeding too fast to allow waiting for comprehensive conventional-force limitations. Thus a specific approach focusing just on armed UVs is advisable. Elements of this approach are described in the following. Armed UAVs are most advanced and pose the strongest threats, so they should have the first priority. UGVs come next, while maritime UVs (USVs and UUVs) are less urgent. In order to make possible fast conclusion of limitations on the new kinds of armed UVs, the existing ones should be accepted for the time being; their reduction/limitation needs more progress and would take more time. ${ }^{52}$

\section{New limits for armed UAVs}

For limitation of armed uninhabited air vehicles it is sensible to divide them into different categories: fixed-/

\footnotetext{
$\overline{51}$ For possible criteria defining new sub-categories see "New limits for armed UAVs".

52 This holds for nuclear and conventional ballistic and cruise missiles, guided missiles for ship and air defence, torpedoes etc. To reduce grey areas a criterion could be defined that "existing" means "deployed already in 2000".
} 
Table 1 National limits for major weapon systems for ten selected countries in the Adapted CFE Treaty (1999) (not in force) (CFE Treaty 1999: Protocol on National Ceilings)

\begin{tabular}{|c|c|c|c|c|c|}
\hline State party & Battle tanks & Armoured combat vehicles (total) & Pieces of artillery & Combat aircraft & Attack helicopters \\
\hline Armenia & 220 & 220 & 285 & 100 & 50 \\
\hline Belgium & 300 & 989 & 288 & 209 & 46 \\
\hline Czech Republic & 957 & 1,367 & 767 & 230 & 50 \\
\hline Germany & 3,444 & 3,281 & 2,255 & 765 & 280 \\
\hline Norway & 170 & 275 & 491 & 100 & 24 \\
\hline Russia & 6,350 & 11,280 & 6,315 & 3,416 & 855 \\
\hline Turkey & 2,795 & 3,120 & 3,523 & 750 & 130 \\
\hline Ukraine & 4,080 & 5,050 & 4,040 & 1,090 & 330 \\
\hline UK & 843 & 3,017 & 583 & 855 & 350 \\
\hline USA & 1,812 & 3,037 & 1,553 & 784 & 396 \\
\hline
\end{tabular}

Ceilings for sub-categories "Armoured Infantry Fighting Vehicles" and "Heavy Armament Combat Vehicles" under "Armoured Combat Vehicles" and footnotes for sub-ceilings in active units have been removed. The full table contains 30 countries

variable-wing aircraft and helicopters, plus special types such as airships or paragliders.

For armed uninhabited fixed/variable wing aircraft and helicopters national limits should be agreed globally or by region. An idea on the national limits outside of Europe can be gained from the ceilings of the Adapted CFE Treaty (1999) (which is not in force), Table 1 lists them for selected countries. Ideally the armed-UAV limits would be markedly lower so that the totals over inhabited and uninhabited combat aircraft and attack helicopters remain in the same range. ${ }^{53}$

For globally active military powers limits in several regions would hold in parallel. In case uninhabited heavy bombers will be introduced, they should form a category of their own, with special limits lower than those for the other combat aircraft. For a global solution air vehicles of the navies with and without crew will have to be regulated as well.

In case countries will put much emphasis on armed UAVs that are significantly smaller than traditional combat aircraft or attack helicopters (the empty masses of which are in the range of 10-20 metric tons and $1-8$ tons, respectively), ${ }^{54}$ it is unrealistic to expect that these should count in the same way as large ones. To accommodate these motives new subcategories could be introduced, with thresholds of empty

\footnotetext{
53 A treaty just covering armed UAVs would leave air vehicles with crew on board without limits while both types would fulfill the same missions in many cases. It is nevertheless justified due to new dangers from UAVs. However, where achievable the approach taken by the CFE Treaty should be taken: numerical limits on combat aircraft and attack helicopters should hold independently of whether these are uninhabited or not, with notification of types and holdings of unarmed military air vehicles that are similar to armed ones.

54 Maximum take-off masses are in the range 15-40 $t$ for combat aircraft and 2-10 t for attack helicopters. Strategic bombers have empty and take-off masses in the ranges 70-110 t and 150-300 t, respectively.
}

masses at, for example, 100 and 1,000 kg for combat aircraft and 50 and $500 \mathrm{~kg}$ for attack helicopters. Taking into account that smaller UAVs are cheaper, one can expect arguments for much higher maximum holdings than for the larger/heavier ones. However, acknowledging that high numbers can bring specific possibilities for surprise attack and destabilisation, the maximum holdings in the lightweight armed-UAV categories should not transgress a few times the limits in the normal-weight classes.

In order to maintain and increase military stability, at some point it may become advisable to introduce qualitative criteria beyond take-off mass which gives a rough implicit limit on weapons payload. Further criteria usable in the definition of refined armed-UAV categories are mainly payload, maximum range and endurance; however, these are less clearly defined and less easily verifiable.

Special kinds of armed UAVs need their own limits, as soon as their introduction will become probable. For example, for armed uninhabited airships probably the limits can be very low, maybe zero. Armed paragliders could become relevant threats so that their numbers should be strictly limited.

To reduce ambiguity and support verification, types and holdings of unarmed military UAVs should be notified.

\section{New limits for armed UGVs}

Introduction of armed uninhabited ground vehicles will follow arming of UAVs with several to many years delay, but limitation should be taken into view soon. Similarly to the approach recommended for armed UAVs, national limits for uninhabited battle tanks and armoured combat vehicles should be defined so that totals (including inhabited versions) are in line with the approach of the Adapted 
CFE Treaty (see the selected ceilings for Europe in Table 1). ${ }^{55}$ As described for the CFE Treaty, categories and limits for smaller armed UGVs may be needed. Thresholds of unladen weights could be 100 and $1,000 \mathrm{~kg}$, respectively. Similarly to the case of UAVs, payload, range and endurance could be used as additional qualitative criteria. As with UAVs, types and holdings of unarmed UGVs should be notified.

\section{New limits for armed USVs and UUVs}

Concerning maritime UVs, big ships as well as submarines are not likely to be operated without human crews on board. Uninhabited surface vehicles (USVs) ready for deployment or in development are mostly motor boats, with some semi-submersibles in addition. The lengths are below $15 \mathrm{~m}$, with light weapons and maybe a small cannon on board (e.g. US DoD 2009: App. C.1). Compared with battle ships and aircraft carriers, they provide only very limited military capabilities, with little effect on military stability. As long as this situation remains and their numbers remain limited, limitation of USVs is of secondary importance. However, to prevent terrorist uses, at least informal restraint is recommended.

Uninhabited undersea vehicles (UUVs), on the other hand, could change the situation at sea in particular if they could attack surface ships and submarines markedly more effectively than present torpedoes. Limiting (new types of) UUVs poses difficult problems of categorisation and verification and is intimately linked to the problem of maritime arms control in general. Thus a separate agreement focusing on UUVs would not be very useful to solve the stability problem at sea, and states with navies are unlikely to agree to such an approach. Proliferation to non-state groups is not an urgent concern. As a consequence, UUVs would best be treated within comprehensive regulation of naval forces. Such regulation would be very difficult to negotiate and would take a long time.

Should the judgements on USVs and/or UUVs change before, specific limitations should be sought.

\section{Verification}

Verification of compliance with the proposed armed-UV limits can mostly rely on established methods and means, namely national technical means of verification (mainly satellites), co-operative overflights with cameras ${ }^{56}$ and

\footnotetext{
$\overline{55}$ Also here a common ceiling for inhabited and uninhabited armed ground vehicles should be used where achievable, with notification of types and holdings of unarmed military ground vehicles that are similar to armed ones.

56 As in Europe plus USA and Canada under the Open Skies Treaty (1992, in force) (Open Skies Treaty 1992).
}

above all on-site inspections with the right of access not only to sites with holdings of limited vehicles, but also to testing and training sites. Also for sites with holdings of unarmed vehicles that are similar to armed ones there needs to be a right of access. Inspection equipment should be allowed similar to the CFE-Treaty rules. ${ }^{57}$ If new categories using mass thresholds are used, portable scales should be added. ${ }^{58}$ In order to be prepared for a time when small and very small armed UVs will become feasible and/or small and very small UVs will be introduced into civilian society, inspection protocols should allow the use of magnifying equipment as well as contain provisions for challenge inspections at non-military sites. ${ }^{59}$ As a prerequisite for successful inspections, notifications of the existing types of armed UVs and unarmed similar ones with regular updates and of the holdings at the various locations are needed.

To check compliance with the requirement of human control over armed-UV attacks, the ICRC should have access to the recorded sensor, communication and control data on request.

\section{Export controls and transparency measures}

In the field of export controls, UVs should be covered more systematically. In particular the Hague Code of Conduct should add cruise missiles (Gormley 2008) and other UAVs. The Wassenaar Arrangement should be broadened to cover also UGVs, USVs and UUVs. ${ }^{60}$

Concerning transparency measures, confidence and security building measures such as the Vienna Document for Europe would be useful in other regions, covering armed UVs together with all other weapons systems. As long as such comprehensive agreements will not be achievable, special notification regimes concerning armed UVs would help, maybe also as a first step towards substantial limitation agreements.

In the United Nations Register of Conventional Arms it should be checked whether the definitions of its categories should be augmented by explanations that armed UVs are included.

\footnotetext{
57 Portable passive night vision devices, binoculars, video and still cameras, dictaphones, tape measures, flashlights, magnetic compasses and lap-top computers; other equipment needs approval of the inspected State Party (CFE Treaty 1999: Protocol on Inspections).

58 The START I Treaty allows the use of "weighing devices" (beside many other items, e.g. radiation detection equipment) (START I 1991).

59 The requirements would grow as mini-/microrobots would shrink in size, or as insects would be implanted with electronics, a topic of research already now (e.g. Bozkurt et al. 2009).

60 The latter beyond the notion of ,underwater robots”.
} 
Table 2 Arms-control recommendations if a comprehensive ban of armed UVs can be achieved, or if not

\begin{tabular}{|c|c|c|}
\hline Limit & Agreement & Verification by \\
\hline No armed UVs & New global treaty & NTM, OSI (incl. testing, training) \\
\hline No autonomous attack & $\begin{array}{l}\text { New IHL rule with obligation to record all } \\
\text { UV-attack data }\end{array}$ & ICRC after the fact, forensics \\
\hline No uninhabited satellites as/with weapons & General space-weapons ban & NTM, pre-launch inspection \\
\hline No new kinds of uninhabited nuclear carriers & $\begin{array}{l}\text { START follow on, incorporation of the other } \\
\text { NWS }\end{array}$ & NTM, OSI \\
\hline No armed transatmospheric vehicles & New treaty (global or space-faring states) & NTM, OSI (incl. testing) \\
\hline No UVs $<0.2-0.5 \mathrm{~m}$ & New global treaty & $\begin{array}{l}\text { OSI (with magnifying equipment, } \\
\text { including challenge) }\end{array}$ \\
\hline $\begin{array}{l}\text { Numerical limits on remotely controlled armed } \\
\text { UAVs, UGVs }\end{array}$ & $\begin{array}{l}\text { Europe: CFE Treaty } \\
\text { Elsewhere: new treaties (regional or global) } \\
\text { Both with new categories }\end{array}$ & NTM, OSI (incl. testing, training) \\
\hline $\begin{array}{l}\text { Numerical limits on remotely controlled armed } \\
\text { USVs, UUVs }\end{array}$ & $\begin{array}{l}\text { New treaty/ies on naval forces (regional or } \\
\text { global) }\end{array}$ & NTM, OSI \\
\hline
\end{tabular}

$I H L$ international humanitarian law, ICRC International Committee of the Red Cross, NTM national technical means of verification, NWS nuclear-weapon state, $O S I$ on-site inspection, START Strategic Arms Reduction Treaty, $U V$ uninhabited vehicle, $U A V$ uninhabited air vehicle, $U G V$ uninhabited ground vehicle, $U S V$ uninhabited surface vehicle, $U U V$ uninhabited undersea vehicle

Final remarks on recommendations

Table 2 summarises the arms-control options and recommendations with the required verification methods. In actual negotiations many details will have to be discussed and settled about categories, limits, exceptions, verification methods. For many such questions the CFE Treaty and the Vienna Document can provide useful ideas. In other areas new ground will have to be covered, for example concerning the inclusion of civilian UVs in transparency measures and verification, or with respect to the ban on autonomous targeting.

With the use of the term "vehicle" immobile armed robots (weapons fixed at a site without a human operator in the immediate vicinity) are excluded from the present recommendations. Further research should investigate whether their international limitation is useful and if so, how it could be arranged.

The outlook for acceptance of the recommendations is mixed. Given the strong increase in UAV attacks during the last decade and the explicit goal of expansion of armed UVs in the USA, and the intention of many more countries to follow this role model, a complete ban is not realistic for the time being. Additional difficulties arise from the propensity of democracies toward warfare with less risk to their soldiers (Sauer and Schörnig 2012). On the other hand, democratic society opens the possibility for nongovernmental organisations (NGOs) and expert groups to create public awareness. In the cases of anti-personnel land mines and cluster munitions military interests in these systems were overruled finally and prohibition conventions were concluded, mainly because of civilian victims. Present UAV attacks cause markedly fewer civilian casualties, but their number is not insignificant (e.g. Woods and Ross 2012). Concerning the proposed ban on autonomous armed UVs, the influential NGO Human Rights Watch has taken up this demand (HRW/IHRC 2012). With respect to limits on remotely controlled armed UVs, political action is already required to maintain and revive some of the existing regulation, all the more to expand it. But the agreements in place provide important precedents to build on for NGOs as well as for supportive states.

\section{Conclusion}

Armed UVs pose ethical issues not only with respect to their use in armed conflict, but also concerning the prevention of war. In order to prevent dangers for arms control, international humanitarian law, for military stability as well as for society, armed UVs should be limited, some categories should be prohibited at all. Existing regulation, in particular the $\mathrm{CFE}$ Treaty, encompasses armed UVs already, but additional preventive-arms-control measures are recommended.

This analysis has presented ideas for such measures. Most urgent is the field of armed UAVs. Actual negotiation requires designing categories, limitations and verification methods in more detail. Given political will, the dangers from armed UVs can be contained using established methods of (preventive) arms control.

Acknowledgments Most of this research was done during a project funded by the German Foundation for Peace Research (DSF), I want to thank the DSF for their support. Thanks go to Hans-Joachim Schmidt (Peace Research Institute Frankfurt) and the Zentrum für Verifikationsaufgaben der Bundeswehr for information on the status 
of the CFE Treaty. In addition I am grateful to three anonymous reviewers for valuable comments.

Open Access This article is distributed under the terms of the Creative Commons Attribution License which permits any use, distribution, and reproduction in any medium, provided the original author(s) and the source are credited.

\section{References}

Altmann, J. (2001). Military uses of microsystem technologiesdangers and preventive arms control. Münster: Agenda.

Altmann, J. (2006). Military nanotechnology: Potential applications and preventive arms control. Abingdon/New York: Routledge.

Altmann, J. (2009). Preventive arms control for uninhabited military vehicles. In R. Capurro \& M. Nagenborg (Eds.), Ethics and robotics. Heidelberg: AKA.

Altmann, J. (2012). Armed robots and preventive arms control. In M. Decker \& M. Gutmann (Eds.), Robo- and informationethicssome fundamentals. Lit: Münster.

Altmann, J., \& Gubrud, M. (2004). Anticipating military nanotechnology. IEEE Technology and Society Magazine, 23(4), 33-40.

Altmann, J., \& Scheffran, J. (2003). New rules in outer space: Options and scenarios. Security Dialogue, 34(1), 109-116.

Arkin, R. C. (2009). Governing lethal behavior in autonomous robots. Boca Raton FL: Chapman\&Hall/CRC.

Asaro, P. (2008). How just could a robot war be? In P. Brey, A. Briggle, \& K. Waelbers (Eds.), Current issues in computing and philosophy. Amsterdam: IOS.

Australia Group. (2011a). Control list of dual-use biological equipment and related technology and software. Available at http://www.australiagroup.net/en/dual_biological.html. 25 January 2012.

Australia Group. (2011b). Control list of dual-use chemical manufacturing facilities and equipment and related technology and software. Available at http://www.australiagroup.net/en/dual chemicals.html. 25 January 2012.

BTWC (Biological and Toxin Weapons Convention). (1972). Convention on the prohibition of the development, production and stockpiling of bacteriological (Biological) and toxin weapons and on their destruction. Available at http://www.opbw.org/ convention/conv.html. 23 January 2012.

Boothby, B. (2011). The law relating to unmanned aerial vehicles, unmanned combat aerial vehicles, and intelligence gathering from the air. Humanitäres-Völkerrecht-Informationsschriften. Journal of International Law of Peace and Armed. Conflict, 24(2), 81-91.

Bozkurt, A., Gilmour, R. F., Sinha, A., Stern, D., \& Lal, A. (2009). Insect-machine interface based neurocybernetics. IEEE Transactions on Biomedical Engineering, 56(6), 1727-1733.

Canning, J. (2006). A concept of operations for armed autonomous systems. In Presented at 3rd annual disruptive technology conference, Washington DC (6-7 September). Available at http:// www.dtic.mil/ndia/2006disruptive_tech/. 14 December 2012.

CFE Treaty. (1990). Treaty on conventional armed forces in Europe. Available at http://www.osce.org/library/14087. 23 January 2012.

CFE Treaty. (1999). Agreement on adaptation of the treaty on conventional armed forces in Europe. Available at http://www. osce.org/library/14108. 23 January 2012.

CTBT. (1996). Comprehensive Nuclear-Test-Ban Treaty. Available at http://www.ctbto.org/fileadmin/content/treaty/treaty_text.pdf. 13 March 2013.
CWC (Chemical Weapons Convention). (1993). Convention on the prohibition of the development, production, stockpiling and use of chemical weapons and on their destruction. Available at http://www.opcw.org/chemical-weapons-convention/. 23 January 2012.

Daly, M. (Ed.) (2008). Jane's unmanned aerial vehicles and targets, Issue 31. Coulsdon: Jane's.

Daly, M. (Ed.) (2010). Jane's unmanned aerial vehicles and targets, Issue 35. Coulsdon: Jane's.

Dean, R. (1982). The case for negotiated disarmament. In G. Goodwin (Ed.), Ethics and nuclear deterrence. London/Canberra: Croom Helm.

Finnis, J., Boyle, J. M., \& Grisez, G. (1987). Nuclear deterrence, morality and realism. Oxford: Clarendon.

Fisher, D. (1985). Morality and the bomb: An ethical assessment of nuclear deterrence. London: Croom Helm.

Goldblat, J. (2002). Arms control-the new guide to negotiations and agreements. London: SAGE.

Gormley, D. (2008). Missile contagion: Cruise missile proliferation and the threat to international security. Westport, CT: Praeger.

Grego, L. (2012). A history of anti-satellite programs. Cambridge MA: Union of Concerned Scientists. Available at http://www. ucsusa.org/assets/documents/nwgs/a-history-of-ASAT-programs_ lo-res.pdf. 25 July 2012.

HCOC. (2011). Hague code of conduct against ballistic missile proliferation. Available at http://www.bmeia.gv.at/en/foreign-ministry/ foreign-policy/disarmament/weapons-of-mass-destruction/hcoc. html (20 Jan. 2012).

Heyns, C. (2012). Report of the special rapporteur on extrajudicial, summary or arbitrary executions, Christof Heyns; Follow-up to country recommendations: United States of America, United Nations, General Assembly, Human Rights Council, A/HRC/20/ 22/Add.3, 30 March 2012. Available at http://www.ohchr.org/ Documents/HRBodies/HRCouncil/RegularSession/Session20/AHRC-20-22-Add3_en.pdf. 14 December 2012.

HRW (Human Rights Watch)/IHRC (International Human Rights Clinic (IHRC) at Harvard Law School). (2012). Losing humanity: The case against killer robots. New York NY: HRW/ Cambridg MA: IHRC. Available at http://www.hrw.org/ reports/2012/11/19/losing-humanity. 20 November 2012.

ICRAC (International Committee for Robot Arms Control). (2009). Mission statement. Available at http://icrac.net/statements/. 25 July 2012.

INF Treaty. (1987). Treaty between the United States of America and the Union of Soviet Socialist Republics on the elimination of their intermediate-range and shorter-range missiles. Available at http://www.state.gov/www/global/arms/treaties/inf1.html. 30 January 2012.

Krishnan, A. (2009). Killer robots-legality and ethicality of autonomous weapons. Farnham Surrey/Burlington VT: Ashgate.

Lin, P., Bekey, G., \& Abney, K. (2009). Robots in war: Issues of risk and ethics. In R. Capurro \& M. Nagenborg (Eds.), Ethics and robotics. Heidelberg: AKA.

Lowther, A. B. (2009). Unmanned and nuclear-is America ready for a UAV bomber? Armed Forces Journal (June). Available at http://www.armedforcesjournal.com/2009/06/4040349. 26 January 2012.

Marchant, G. E., et al. (2011). International governance of autonomous military robots (pp. 272-315). XII: The Columbia Science and Technology Law Review.

Millett, P. (Ed.). (2011). Improving implementation of the biological weapons convention: The 2007-2010 intersessional process. New York/Geneva: United Nations.

MTCR (Missile Technology Control Regime). (2011). Equipment, software and technology annex, MTCR/TEM/2011/Annex. 
Available at http://www.mtcr.info/english/MTCR-April2011-Tech nical-Annex.pdf. 20 January 2012.

New START (New Strategic Arms Reduction Treaty). (2010). New START treaty enters into force. Available at http://www.state. gov/t/avc/newstart/. 26 January 2012.

NSG (Nuclear Suppliers Group). (2011). Available at http://www. nuclearsuppliersgroup.org. 25 January 2012.

NPT (Nuclear Non-Proliferation Treaty). (1968). Treaty on the NonProliferation of Nuclear Weapons. Available at http://www. iaea.org/Publications/Documents/Infcircs/Others/infcirc140.pdf. 13 March 2013

Open Skies Treaty. (1992). Treaty on open skies. Available at www.osce.org/library/14127. 25 January 2012.

OST (Outer Space Treaty). (1967). Treaty on principles governing the activities of states in the exploration and use of outer space, including the moon and other celestial bodies. Available at http://www.state.gov/www/global/arms/treaties/space1.html. 30 January 2012.

PTBT (Partial Test-Ban Treaty). (1963). Treaty banning nuclear weapon tests in the atmosphere, in outer space and under water. Available at http://www.un.org/disarmament/WMD/Nuclear/pdf/ Partial_Ban_Treaty.pdf. 13 March 2013.

RAF (Royal Air Force). (2012). Reaper. Available at http://www. raf.mod.uk/equipment/reaper. 14 December 2012.

Sanger, D. E., \& Shanker, T. (2010). U.S. faces choice on new weapons for fast strikes. New York Times, 22 April.

Sauer, F., \& Schörnig, N. (2012). Killer Drones-the silver bullet of democratic warfare? Security Dialogue, 43(4), 353-370.

Schmidt, H.-J. (2008). End or realignment of conventional arms control? (in German), HSFK-Report Nr. 3/2008. Frankfurt/M.: Peace Research Institute Frankfurt.

Schmidt, H.-J., \& Hartmann, R. (2011). Conventional arms control in Europe-Pathways into the future (in German), HSFK-Report Nr. 06/2011, Frankfurt/M.: Peace Research Institute Frankfurt.

Sharkey, N. (2010). Saying 'No!' to lethal autonomous targeting. Journal of Military Ethics, 9(4), 369-383.

Sharkey, N. (in press). The evitability of autonomous robot warfare. International Review of the Red Cross.

Singer, P. W. (2009). Wired for war-The robotics revolution and conflict in the twenty-first century. New York, NY: Penguin.

Sparrow, R. (2007). Killer robots. Journal of Applied Philosophy, 24(1), 62-77.

Sparrow, R. (2009). Predators or plowshares? Arms control of robotic weapons. IEEE Technology and Society Magazine, 28(1), 25-29.

Sparrow, R. (2011). Robotic weapons and the future of war. In J. Wolfendale \& P. Tripodi (Eds.), New wars and new soldiers: Military ethics in the contemporary world (pp. 117-133). Surrey UK \& Burlington VA: Ashgate.

START I (Strategic Arms Reduction Treaty). (1991). Annex 8 to the inspection protocol. Available at http://www.state.gov/www/ global/arms/starthtm/start/inannex.html. 26 January 2012.

Statement. (2010). Statement of the 2010 expert workshop on limiting armed tele-operated and autonomous systems, Berlin, 20-22 September 2010. Available at http://icrac.net/statements/. 25 July 2012.

UN (United Nations) Charter. (1945). Charter of the United Nations. Available at http://www.un.org/en/documents/charter/index.shtml. 30 January 2012.

UN GA (United Nations General Assembly). (1961). Question of disarmament, A/RES/1722(XVI). Avalailable at http://daccess-ods. un.org/access.nsf/Get?Open\&DS=A/RES/1722(XVI)\&Lang=E\& Area=RESOLUTION. 25 January 2012.
UN GA (United Nations General Assembly). (2012). Prevention of an arms race in outer space, A/RES/67/30. Available via https:// www.un.org/en/ga/67/resolutions.shtml. 18 March 2013.

UN (United Nations) Register. (2007). United Nations register of conventional arms-information booklet 2007, New York: UN. Available at http://www.un.org/disarmament/convarms/Register/ DOCS/ReportingGuides/InfoBooklet2007/MOD\%20ENGLISH. PDF. 30 January 2012.

UN (United Nations) Register. (2011). Transparency in armamentsreporting to the United Nations register of conventional arms-fact sheet, New York: UN. Available at http://www.un.org/disarmament/convarms/Register/DOCS/20111013RegisterFactsheet.pdf. 30 January 2012.

UN SC (United Nations Security Council). (2001). Resolution 1386, S/RES/1386 (2001). Available at http://daccess-ods.un.org/TMP/ 3692268.13316345.html. 26 January 2012.

UN SG (United Nations Secretary-General). (2008-2012). United Nations register of conventional arms-report of the secretarygeneral. A/63/120, A/64/135, A/65/133, A/66/127, A/67/212. Available via http://www.un.org/disarmament/convarms/Register. 12 March 2013.

US DoD (Department of Defense). (2007). Unmanned systems roadmap 2007-2032. Washington, DC: US Department of Defense. Available at http://www.dtic.mil/cgi-bin/GetTRDoc?Location=U2\&doc=Get TRDoc.pdf\&AD=ADA475002. 30 January 2012.

US DoD (Department of Defense). (2009). FY2009-2034 unmanned systems integrated roadmap. Washington DC: US Department of Defense. Available at www.acq.osd.mil/uas/docs/UMSIntegrated Roadmap2009.pdf. 30 January 2012.

US DoD (Department of Defense). (2012). Autonomy in weapon systems. Directive Number 3000.09, Washington, DC: US Department of Defense. Available at http://www.dtic.mil/whs/directives/corres/ pdf/300009p.pdf. 14 December 2012.

US GAO (United States Government Accountability Office). (2012). Agencies could improve information sharing and end-use monitoring on unmanned aerial vehicle exports. GAO-12-536. Washington DC: GAO. Available at http://www.gao.gov/assets/600/59 3131.pdf. 14 January 2013.

VD (Vienna Document). (2011). Vienna document 2011 on confidence- and security-building measures, FSC.DOC/1/11. Available at http://www.osce.org/fsc/86597. 18 January 2012.

Walzer, M. (1977). Just and unjust wars-a moral argument with historical illustrations. New York: Basic.

Wan, W., \& Finn, P. (2011). Global race on to match U.S. drone capabilities. Washington Post, 4 July.

Wassenaar. (2011) The Wassenaar arrangement on export controls for conventional arms and dual-use goods and technologies. List of dualuse goods and technologies and munitions list. Available via http://www.wassenaar.org/controllists/index.html. 20 January 2012.

Woods, C., \& Ross, A. K. (2012). Revealed: US and Britain launched 1,200 drone strikes in recent wars. The Bureau of Investigative Journalism (Dec. 4). Available at: http://www.thebureauinvestigates.com/2012/12/04/revealed-us-and-britain-launched-1200drone-strikes-in-recent-wars/. 17 December 2012.

Zangger (Zangger Committee). (2011). Available at http://www. zanggercommittee.org. 25 January 2012. 